\title{
TRIB1 rs17321515 gene polymorphism increases the risk of coronary heart disease in general population and non-alcoholic fatty liver disease patients in Chinese Han population
}

Qun Liu ${ }^{1,4 \dagger}$, Shou-Sheng Liu ${ }^{3,5+}$, Zhen-Zhen Zhao ${ }^{3,5}$, Ben-Tian Zhao ${ }^{2}$, Shui-Xian Du², Wen-Wen Jin ${ }^{2}$ and Yong-Ning $\operatorname{Xin}^{1,2,4,5^{*}}$

\begin{abstract}
Background: Present evidences suggested that TRIB1 rs17321515 polymorphism was tightly associated with the increased risk of NAFLD and CHD. CHD is one of the main complications of NAFLD, whether TRIB1 rs 17321515 polymorphism could affect the risk of CHD in general population and NAFLD patients in Chinese Han population was remain unknown. The present study was designed to investigate the association between TRIB1 rs17321515 polymorphism and the risk of CHD in general population and NAFLD patients in Chinese Han population, and investigate the effect of TRIB1 rs17321515 polymorphism on serum lipid levels.
\end{abstract}

Patients and methods: TRIB1 rs17321515 gene polymorphism was genotyped using the polymerase chain reaction (PCR) in healthy controls $(n=175)$, CHD patients $(n=155)$, NAFLD patients $(n=146)$, and NAFLD+CHD patients $(n=156)$. Serum lipid profiles were determined using biochemical methods. Statistical analyses were performed using SPSS 24.0 statistical software.

Results: The TRIB1 rs17321515 AA+GA genotypes were the significant risk factors for the CHD in general population $(\mathrm{OR}=1.788 ; 95 \% \mathrm{Cl}: 1.104-2.897 ; P=0.018)$ and in the NAFLD patients $(\mathrm{OR}=1.760 ; 95 \% \mathrm{Cl}: 1.071-2.891 ; P=0.026)$. After adjusted for age, gender, and body mass index, the risk for $\mathrm{CHD}$ in general population $(\mathrm{OR}=1.857 ; 95 \% \mathrm{Cl}$ : 1.116-3.089; $P=0.017)$ and NAFLD patients was still significant $(\mathrm{OR}=1.723 ; 95 \% \mathrm{Cl}: 1.033-2.873 ; P=0.037)$. In addition, TRIB1 rs17321515 A carriers possess the higher lipid profiles in the included subjects.

Conclusions: TRIB1 rs17321515 AA+GA genotypes were significant associated with the risk of CHD in general population and in NAFLD patients in Chinese Han population. The rs17321515 A allele increases the serum lipid profiles in included subjects.

Keywords: Non-alcoholic fatty liver disease, TRIB1, Coronary heart disease, Polymorphism, Lipids metabolism

\footnotetext{
* Correspondence: xinyongning@163.com

${ }^{\dagger}$ Qun Liu and Shou-Sheng Liu contributed equally to this work.

${ }^{1}$ The Affiliated Qingdao Municipal Hospital of Qingdao University, Qingdao 266011, China

2Department of Infectious Disease, The Affiliated Qingdao Municipal Hospital

of Qingdao University, 1 Jiaozhou Road, Qingdao 266011, Shandong

Province, China

Full list of author information is available at the end of the article
}

(c) The Author(s). 2019 Open Access This article is distributed under the terms of the Creative Commons Attribution 4.0 International License (http://creativecommons.org/licenses/by/4.0/), which permits unrestricted use, distribution, and reproduction in any medium, provided you give appropriate credit to the original author(s) and the source, provide a link to the Creative Commons license, and indicate if changes were made. The Creative Commons Public Domain Dedication waiver (http://creativecommons.org/publicdomain/zero/1.0/) applies to the data made available in this article, unless otherwise stated. 


\section{Background}

Non-alcoholic fatty liver disease (NAFLD) is defined histologically as when more than $5 \%$ of liver cells are found to be suffering from steatosis, which is the manifestation of metabolic syndrome in liver [1]. The disease spectrum of NAFLD includes non-alcoholic fatty liver (NAFL), non-alcoholic steatohepatitis (NASH), fibrosis, liver cirrhosis and even hepatocellular carcinoma [2]. NAFLD has exceeded viral hepatitis and become the most prevalent liver disease in the world, and become the second largest cause of liver transplantation and the third largest cause of liver cancer [3]. Coronary heart disease (CHD) is a form of the metabolic syndrome, more and more epidemiology and clinical studies had been conducted to investigate the tightly association of NAFLD and CHD [4]. Increased evidences suggested that NAFLD is not only a marker of CHD and other structural, functional and arrhythmia complications, but also takes effects in the development and progression of these cardiac complications $[5,6]$. Therefore, patients with NAFLD will benefited from the more rigorous monitoring and early treatment interventions to reduce the risk of $\mathrm{CHD}$ and other cardiac and arrhythmia complications.

NAFLD and CHD possess several the same influence factors such as lipids metabolism disorder, obesity and insulin resistance [7]. In addition, genetic factor such as gene polymorphism was also the significant risk factor for the NAFLD and CHD [8-11]. Genome-wide association study (GWAS) revealed many gene polymorphisms such as PNPLA3 rs738409 and TM6SF2 rs58542926 which were the significant risk factors for NAFLD [12, 13]. Abundant studies revealed that gene polymorphisms such as $C D 36$ rs1761667, CDKN2BAS rs496892, and COX2 -765G > $\mathrm{C}$ were tightly associated with the risk of CHD in different countries [14-16]. Tribbles 1 (TRIB1) encoding Tribbles protein homolog 1 [17], proteins from the tribbles family include a MEK1-binding domain, an E3 ubiquitin ligase (COP1)-binding domain, and a pseudokinase domain, all of which are significant by interacting with respective partners [18]. GWAS in American identified that lots of novel genomic loci participated in the regulation of plasma triglyceride (TG) levels. One of those loci was the 8q24 locus, with the lead single nucleotide polymorphism (SNP) involving a linkage-disequilibrium block that contains the gene TRIB1 [19]. Although TRIB1 undergoes miRNA regulation, it is quite conserved in parts, containing a long $1.5 \mathrm{Kbp} \mathrm{3}$ ' untranslated region (UTR) [20]. Under normal physiological conditions, TRIB1 can negatively regulate carbohydrate-responsive element-binding protein (ChREBP) via proteasome proteolysis ubiquitination, raising the microsomal triglyceride transfer protein (MTTP) to terminate lipogenesis. In the absence of TRIB1, the process of lipogenesis is aberrant and the serum lipid disorders was occurred [21]. GWAS studies have repeatedly confirmed that TRIB1 gene polymorphisms were associated with dyslipidemia [22-25], and several studies had shown that TRIB1 gene variants can increase the risk of $\mathrm{CHD}[26,27]$. In addition, previous studies have confirmed that TRIB1 gene variation can also increase the risk of NAFLD [28-30].

In consideration of the prevalent complication of NAFLD and CHD, understanding of effect of genetic factors on the patients with NAFLD and CHD were

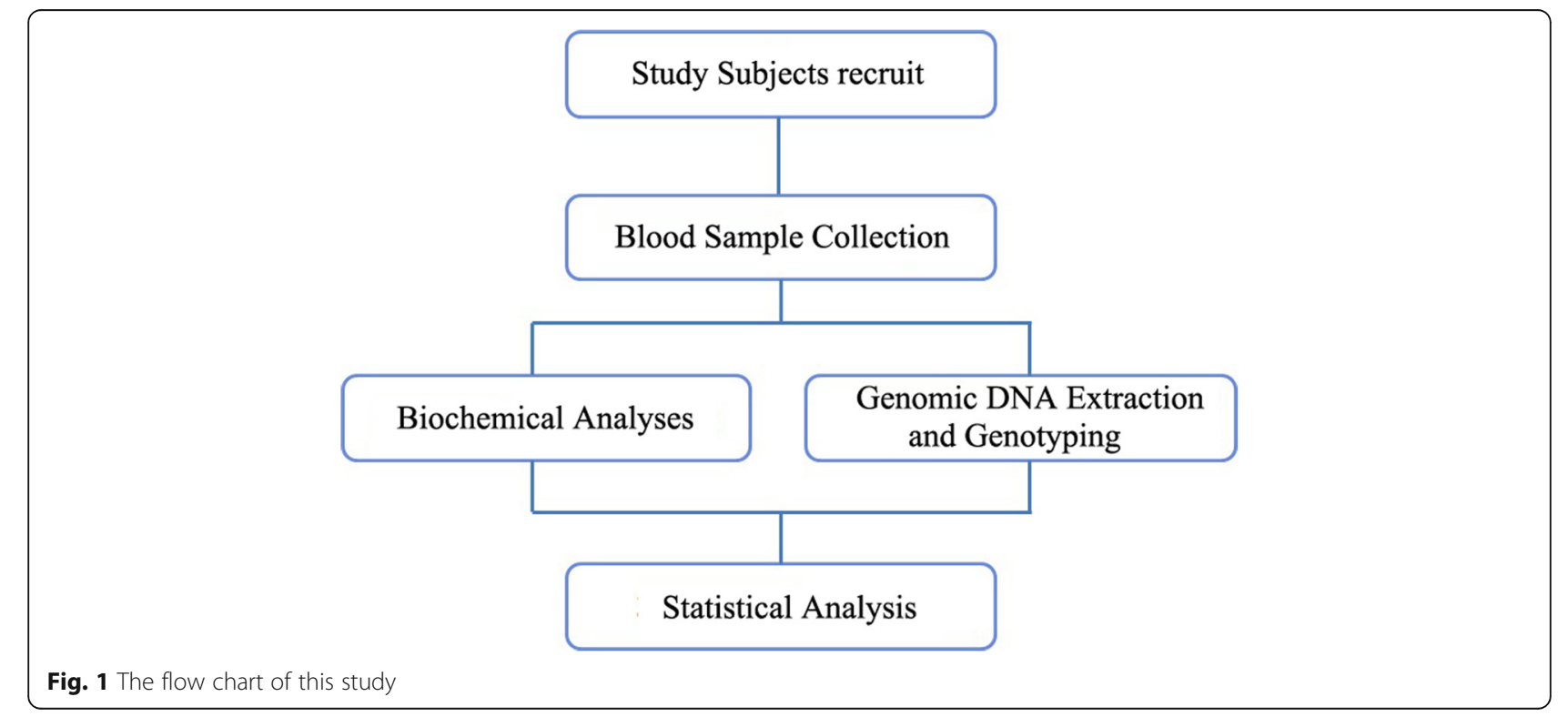


Table 1 Clinical Characteristics of CHD Patients and Healthy controls

\begin{tabular}{|c|c|c|c|c|}
\hline Parameters & $\mathrm{CHD}(n=155)$ & Controls $(n=175)$ & Statistics & $P$ value \\
\hline Male/Female & $83 / 72$ & $88 / 87$ & $x^{2}=0.350$ & 0.554 \\
\hline Age, y & $60.00(59.00,75.00)$ & $62.00(53.00,68.00)$ & $Z=-1.013$ & 0.311 \\
\hline $\mathrm{BMI}, \mathrm{kg} / \mathrm{m}^{2}$ & $24.20 \pm 2.73$ & $22.44 \pm 2.88$ & $t=5.632$ & $<0.001$ \\
\hline$A L T, U / L$ & $19.21(14.57,33.40)$ & $17.96(12.57,24.20)$ & $Z=-2.239$ & 0.025 \\
\hline AST, U/L & $22.45(16.70,37.78)$ & $20.78(17.60,24.35)$ & $Z=-1.924$ & 0.054 \\
\hline GGT, U/L & $23.75(17.09,36.74)$ & $19.91(15.24,29.92)$ & $Z=-2.117$ & 0.034 \\
\hline$A L P, U / L$ & $83.84(66.72,109.08)$ & $69.71(57.27,83.63)$ & $Z=-1.083$ & 0.279 \\
\hline $\mathrm{TG}, \mathrm{mmol} / \mathrm{L}$ & $1.23(0.90,1.61)$ & $1.12(0.86,1.62)$ & $Z=-3.026$ & 0.002 \\
\hline $\mathrm{TC}, \mathrm{mmol} / \mathrm{L}$ & $4.19(3.71,5.13)$ & $4.64(3.66,5.18)$ & $Z=-1.525$ & 0.127 \\
\hline $\mathrm{HDL}, \mathrm{mmol} / \mathrm{L}$ & $1.00(0.85,1.20)$ & $1.31(1.05,1.47)$ & $Z=-7.493$ & $<0.001$ \\
\hline $\mathrm{LDL}, \mathrm{mmol} / \mathrm{L}$ & $2.49(2.06,3.18)$ & $3.01(2.61,3.56)$ & $Z=-3.552$ & $<0.001$ \\
\hline TBIL, $\mu \mathrm{mol} / \mathrm{L}$ & $13.50(10.60,17.96)$ & $12.10(9.50,15.10)$ & $Z=-0.366$ & 0.714 \\
\hline $\mathrm{FPG}, \mathrm{mmol} / \mathrm{L}$ & $5.02(4.49,6.02)$ & $4.54(4.06,5.05)$ & $Z=-5.879$ & $<0.001$ \\
\hline pharmacological history & lipid-lowering drug & / & & \\
\hline
\end{tabular}

Abbreviations: $A L P$, alkaline phosphatase; $A L T$, alanine aminotransferase; $A S T$, aspartate aminotransferase; $B M I$, body mass index; FPG, fasting plasma glucose; GGT, Y-glutamyltransferase; $H D L$, high-density lipoprotein; $L D L$, low-density lipoprotein; $T B I L$, total bilirubin; $T C$, total cholesterol; $T G$, triglyceride

urgent and remains to be explored. The aim of this study was to investigate the association of TRIB1 rs17321515 gene polymorphism with the risk of CHD in NAFLD patients in Chinese Han population, and investigate the effect of TRIB1 rs17321515 on the serum lipid profiles of patients with NAFLD and CHD.

\section{Patients and methods}

\section{Study subjects}

This study was approved by the Ethical Committee of Qingdao Municipal Hospital (Qingdao, China), and this study was conducted in accordance with the principles of the Helsinki declaration and its appendices [31]. All the subjects had signed the informed consent before participating in this study.

From June 2018 to November 2018, 146 NAFLD patients (65 females and 81 males, median age 64.00 years) diagnosed by B-type ultrasonography, $155 \mathrm{CHD}$ patients (72 females and 83 males, median age 60.00 years) diagnosed by coronary angiography, 156 patients (80 females and 76 males, median 64.00 years) with both NAFLD and CHD diagnosed by B-type ultrasonography and coronary angiography, and 175 healthy controls (87 females and 88 males, median 62.00 years) that matched for sex and age were enrolled in this study. Clinical data of all the subjects were collected from the department of Gastroenterology

Table 2 Clinical Characteristics of NAFLD+CHD Patients and NAFLD Patients

\begin{tabular}{|c|c|c|c|c|}
\hline Parameters & NAFLD+CHD $(n=156)$ & $\operatorname{NAFLD}(n=146)$ & Statistics & $P$ value \\
\hline Male/Female & $76 / 80$ & $81 / 65$ & $x^{2}=0.421$ & 0.516 \\
\hline Age, y & $64.00(59.00,72.75)$ & $64.00(45.00,74.00)$ & $Z=-0.644$ & 0.520 \\
\hline $\mathrm{BMI}, \mathrm{kg} / \mathrm{m}^{2}$ & $25.47(23.05,27.68)$ & $26.35(24.86,28.49)$ & $Z=-3.431$ & 0.001 \\
\hline$A L T, U / L$ & $23.58(16.07,34.36)$ & $22.67(18.30,35.68)$ & $Z=-0.919$ & 0.358 \\
\hline AST, U/L & $21.29(16.80,32.02)$ & $21.55(18.38,28.09)$ & $Z=-0.647$ & 0.517 \\
\hline GGT, U/L & $30.70(21.31,42.67)$ & $32.55(20.97,47.79)$ & $Z=-0.986$ & 0.324 \\
\hline$A L P, U / L$ & $79.52(66.58,96.46)$ & $68.48(59.09,81.81)$ & $Z=-3.124$ & 0.002 \\
\hline $\mathrm{TG}, \mathrm{mmol} / \mathrm{L}$ & $1.58(1.13,2.18)$ & $1.54(1.16,2.21)$ & $Z=-0.145$ & 0.885 \\
\hline $\mathrm{TC}, \mathrm{mmol} / \mathrm{L}$ & $4.64(3.75,5.54)$ & $5.42(4.98,6.02)$ & $Z=-1.682$ & 0.093 \\
\hline $\mathrm{HDL}, \mathrm{mmol} / \mathrm{L}$ & $1.02(0.88,1.12)$ & $1.19(1.05,1.32)$ & $Z=-6.741$ & $<0.001$ \\
\hline $\mathrm{LDL}, \mathrm{mmol} / \mathrm{L}$ & $2.86(2.10,3.45)$ & $3.30(2.97,3.52)$ & $Z=-1.332$ & 0.183 \\
\hline TBIL, $\mu \mathrm{mol} / \mathrm{L}$ & $12.70(9.70,16.77)$ & $12.00(10.00,14.90)$ & $Z=-0.842$ & 0.040 \\
\hline $\mathrm{FPG}, \mathrm{mmol} / \mathrm{L}$ & $5.70(4.68,6.96)$ & $4.96(4.52,5.79)$ & $Z=-3.503$ & $<0.001$ \\
\hline
\end{tabular}

Abbreviations: ALP, alkaline phosphatase; $A L T$, alanine aminotransferase; $A S T$, aspartate aminotransferase; BMI, body mass index; FPG, fasting plasma glucose; GGT, Y-glutamyltransferase; $H D L$, high-density lipoprotein; $L D L$, low-density lipoprotein; $T B I L$, total bilirubin; $T C$, total cholesterol; $T G$, triglyceride 
Table 3 Results of the Hardy-Weinberg Equilibrium

\begin{tabular}{lll}
\hline & $x^{2}$ & $P$ value \\
\hline Control & 1.693 & 0.193 \\
CHD & 0.091 & 0.762 \\
NAFLD $+C H D$ & 0.003 & 0.957 \\
NAFLD & 0.403 & 0.526 \\
\hline
\end{tabular}

and Cardiology, and the Medical center of Qingdao Municipal Hospital. All the individuals were unrelated Northern Han Chinese origin. NAFLD was diagnosed by a standard clinical evaluation, according to the criteria of the American association for the study of liver diseases (AASLD) [32]. CHD was diagnosed by a percutaneous coronary angiography, with the presence of at least $50 \%$ stenosis in at least one of the coronary arteries. Subjects who had other liver diseases, other cardiac disorders or diabetes mellitus were excluded.

\section{Biochemical analyses}

The basic clinical information (name, gender, age, body height, and weight) were obtained by a standard study questionnaire. The body mass index (BMI) was calculated using the equation that mass $(\mathrm{kg}) /$ height $(\mathrm{m})^{2}$. After a $12-\mathrm{h}$ overnight fasting, blood sample was collected from median vein of each subject, and the blood sample was placed into an ethylene diamine tetraacetic acid (EDTA)-containing tube. The serum levels of alanine aminotransferase (ALT), aspartate aminotransferase (AST), gamma-glutamyltranspeptidase (GGT), alkaline phosphatase (ALP), triglyceride (TG), total cholesterol (TC), high-density lipoprotein (HDL), low-density lipoprotein (LDL), total bilirubin (TBIL), fasting plasma glucose (FPG) were measured by standard clinical laboratory techniques (IChem-540 automatic biochemical analyzer, Shenzhen, China), respectively. Environmental factors were excluded in the study.

\section{Genomic DNA extraction and genotyping}

Blood genomic DNA was isolated with a genomic DNA purification kit (TIANGEN, Beijing, China) according to the manufacturer's instructions and stored at $-20^{\circ} \mathrm{C}$ until use. The genotyping of TRIB1 rs17321515 was conducted using the polymerase chain reaction (PCR). Primers for PCR were 5'-ACGTTGGATGTAGAAGTCCCCTTCCC TTAG-3' and 5' ${ }^{\prime}$-ACGTTGGATGGAACAAGGACTT TCGTCCTC-3'. PCR amplification was performed under the following conditions: an initial denaturation at $94{ }^{\circ} \mathrm{C}$ for $5 \mathrm{~min}$, followed by 45 cycles of denaturing at $94{ }^{\circ} \mathrm{C}$ for $20 \mathrm{~s}$, annealing at $56^{\circ} \mathrm{C}$ for $30 \mathrm{~s}$, and extending at $72{ }^{\circ} \mathrm{C}$ for $1 \mathrm{~min}$. The genotypes of rs17321515 were detected by direct DNA sequencing using the ABI veriti-384 Prism sequence detection system, and the raw data were analyzed using MassARRAY TYPER4.0 software (Agena, Inc). Genotyping was performed in blinded fashion and the success rates were $>95 \%$.

\section{Statistical analysis}

Statistical analysis was performed using the statistical package for the social sciences (SPSS) version 24.0 (SPSS Inc. Chicago, IL, USA). The Hardy-Weinberg equilibrium of expected and observed genotype distribution was analyzed by Pearson's $\chi^{2}$ test. After testing for normality, continuous variables were shown as the mean \pm standard deviation or median (interquartile range) for normal and abnormal distributed parameters, respectively. The t-test and Wilcoxon rank sum test were used for comparison of continuous data between groups. The Genotypes and allele frequencies were evaluated using the $X^{2}$ test. The association between SNP and CHD risk in NAFLD patients was estimated by computing odds ratios (ORs) and 95\% confidence intervals (CI) from the binary logistic regression analyses. $P<0.05$ was considered as statistically significant.

\section{Results}

\section{Clinical characteristics of the study participants}

The flow chart of this study was shown in the Fig. 1. The clinical characteristics of CHD patients and healthy controls are shown in the Table 1 . The two groups were matched for gender and age (all $P>0.05$ ). The CHD patients had higher BMI value and serum levels of ALT, GGT, TG and FPG than healthy controls (all $P<0.05$ ), besides, the serum level of HDL and LDL in CHD patients was significant lower compared to the healthy controls (all $P<0.05$ ). The clinical characteristics of NAFLD+CHD patients and

Table 4 Distributions of the TRIB1 rs17321515 Genotypes and Alleles in the Study Groups

\begin{tabular}{|c|c|c|c|c|c|c|c|c|}
\hline & NAFLD & $\mathrm{CHD}$ & NAFLD+CHD & Control & $x^{2}$ & P 1 & $x^{2}$ & $P 2$ \\
\hline Genotypes & & & & & 5.668 & 0.059 & 5.646 & 0.059 \\
\hline GG & 37 (26.6) & $39(22.8)$ & $60(39.0)$ & 67 (40.6) & & & & \\
\hline$A G$ & $73(52.5)$ & $72(42.1)$ & $72(46.8)$ & $70(42.4)$ & & & & \\
\hline AA & $29(20.9)$ & $30(35.1)$ & $22(14.3)$ & $28(17.0)$ & & & & \\
\hline Alleles & & & & & 4.641 & 0.031 & 5.363 & 0.021 \\
\hline G & $147(52.9)$ & $150(53.2)$ & $192(62.3)$ & $204(61.8)$ & & & & \\
\hline$A$ & $131(47.1)$ & $132(46.8)$ & $116(37.7)$ & $126(38.2)$ & & & & \\
\hline
\end{tabular}

$P$ 1:CHD vs Control; $P$ 2:NAFLD+CHD vs NAFLD 
Table 5 Odds Ratios According to Genotypes of TRIB1 rs17321515 Gene Polymorphism in Study Group

\begin{tabular}{|c|c|c|c|c|c|c|c|c|}
\hline & Unadjusted & & & & Adjusted $^{a}$ & & & \\
\hline & OR $(95 \% \mathrm{Cl})$ & $P 1$ & OR $(95 \% \mathrm{Cl})$ & $P 2$ & OR $(95 \% \mathrm{Cl})$ & $P 1$ & OR $(95 \% \mathrm{Cl})$ & $P 2$ \\
\hline GG & 1 & & 1 & & 1 & & 1 & \\
\hline $\mathrm{GA}+\mathrm{AA}$ & $1.788(1.104-2.897)$ & 0.018 & $1.760(1.071-2.891)$ & 0.026 & $1.857(1.116-3.089)$ & 0.017 & $1.723(1.033-2.873)$ & 0.037 \\
\hline
\end{tabular}

${ }^{a}$ Binary logistic regression model was adjusted for age, gender, and body mass index

$P$ 1: CHD vs Control; $P$ 2: NAFLD+CHD vs NAFLD

NAFLD patients are shown in the Table 2. The NAFLD+CHD patients had higher serum levels of ALP, TBIL, FPG than NAFLD patients (all $P<0.05$ ), lower BMI and HDL than NAFLD patients (all $P<0.05$ ).

\section{Genotype and allele distributions of TRIB1 rs17321515}

The genotype distributions of TRIB1 rs17321515 in the four groups were in accordance with the Hardy-Weinberg equilibrium (all $P>0.05$ ) (Table 3 ). As described in the Table 4, there was significant difference in the allele distribution of TRIB1 rs17321515 between CHD patients and controls group $(P=0.031)$. The TRIB1 rs17321515 $\mathrm{GA}+\mathrm{AA}$ genotypes were the significant risk factor for the development of $\mathrm{CHD}(\mathrm{OR}=1.788$; 95\% CI: $1.104-$ 2.897; $P=0.018$ ), after adjusted for age, gender, and body mass index, the risk of TRIB1 rs17321515 GA + AA genotypes were still marked ( $\mathrm{OR}=1.857$; $95 \% \mathrm{CI}$ : $1.116-3.089$; $P=0.017$ ) (Table 5). In addition, there was significant difference in the allele distribution of TRIB1 rs17321515 between NAFLD+CHD patients and NAFLD group $(P=$ 0.021) (Table 4). The TRIB1 rs17321515 GA + AA genotypes were the significant risk factor for the development of CHD in NAFLD patients $(\mathrm{OR}=1.760 ; 95 \% \mathrm{CI}$ : $1.071-$ 2.891; $P=0.026$ ), after adjusted for age, gender, and body mass index, the risk of TRIB1 rs17321515 GA + AA genotypes were still marked $(\mathrm{OR}=1.723$; 95\% CI: $1.033-$ 2.873; $P=0.037$ ) (Table 5).

\section{Association of the TRIB1 rs17321515 gene polymorphism with clinical parameters characteristics in each group subjects}

We compared the TRIB1 rs17321515 A allele with the clinical characteristics of the four groups to estimate whether the rs17321515 A allele was correlated with clinical parameters. As the results shown in the Table 6, there was no significant difference between the A allele carriers and non-carriers in the overall series and in the NAFLD patients (all $P>0.05$ ) (Tables 6 and 7). Higher serum level of FPG in the A allele carriers was observed compared to the non-carriers in the CHD group $(P=0.021)$ (Table 8$)$. In the NAFLD $+\mathrm{CHD}$ patients, the A allele carriers had the higher serum HDL level than non-carriers $(P=0.015)$ (Table 9). In the healthy controls, the A allele carriers had the higher serum TC level than non-carriers $(P=0.001)$ (Table 10).

\section{Discussion}

NAFLD has become a worldwide public health problem. Clinical experience and epidemiological evidences showed

Table 6 Clinical Characteristics of TRIB1 rs17321515 A allele Carriers and Non-carriers in the Overall Series

\begin{tabular}{|c|c|c|c|c|}
\hline Parameters & Carriers $(n=396)$ & Non-carriers $(n=203)$ & Statistics & $P$ value \\
\hline Male/Female & 206/190 & $104 / 99$ & $x^{2}=0.033$ & 0.855 \\
\hline Age, y & $64.00(54.25,72.00)$ & $65.00(54.00,74.00)$ & $Z=-1.221$ & 0.222 \\
\hline $\mathrm{BMI}, \mathrm{kg} / \mathrm{m}^{2}$ & $24.66(22.51,26.83)$ & $24.73(22.39,26.47)$ & $Z=-0.563$ & 0.573 \\
\hline $\mathrm{ALT}, \mathrm{U} / \mathrm{L}$ & $21.31(15.50,32.31)$ & $20.88(14.42,29.42)$ & $Z=-1.275$ & 0.202 \\
\hline AST, U/L & $21.32(17.63,29.36)$ & $21.13(17.15,26.80)$ & $Z=-0.804$ & 0.422 \\
\hline GGT, U/L & $26.64(18.73,40.29)$ & $25.32(16.85,39.86)$ & $Z=-1.577$ & 0.115 \\
\hline$A L P, U / L$ & $75.65(62.23,91.77)$ & $73.06(59.43,87.69)$ & $Z=-1.691$ & 0.091 \\
\hline $\mathrm{TG}, \mathrm{mmol} / \mathrm{L}$ & $1.41(0.98,1.96)$ & $1.31(0.97,1.83)$ & $Z=-1.427$ & 0.153 \\
\hline $\mathrm{TC}, \mathrm{mmol} / \mathrm{L}$ & $4.72(3.89,5.54)$ & $4.86(4.03,5.41)$ & $Z=-0.603$ & 0.546 \\
\hline $\mathrm{HDL}, \mathrm{mmol} / \mathrm{L}$ & $1.10(0.95,1.31)$ & $1.08(0.93,1.32)$ & $Z=-0.577$ & 0.564 \\
\hline $\mathrm{LDL}, \mathrm{mmol} / \mathrm{L}$ & $3.00(2.36,3.47)$ & $2.99(2.48,3.44)$ & $Z=-0.207$ & 0.836 \\
\hline TBIL, umol/L & $12.70(9.80,16.27)$ & $13.20(10.00,17.00)$ & $Z=-0.692$ & 0.489 \\
\hline $\mathrm{FPG}, \mathrm{mmol} / \mathrm{L}$ & $4.95(4.41,5.77)$ & $4.96(4,41,6.11)$ & $Z=-0.730$ & 0.466 \\
\hline
\end{tabular}


Table 7 Clinical Characteristics of TRIB1 rs17321515 A allele Carriers and Non-carriers in the NAFLD Patients

\begin{tabular}{|c|c|c|c|c|}
\hline Parameters & Carriers $(n=102)$ & Non-carriers $(n=37)$ & Statistics & $P$ value \\
\hline Male/Female & $54 / 48$ & 20/17 & $x^{2}=0.014$ & 0.907 \\
\hline Age,y & $64.00(45.00,74.00)$ & $67.00(45.00,75.50)$ & $Z=-0.851$ & 0.395 \\
\hline $\mathrm{BMI}, \mathrm{kg} / \mathrm{m}^{2}$ & $26.47(24.87,28.74)$ & $26.23(24.62,28.06)$ & $Z=-0.110$ & 0.913 \\
\hline $\mathrm{ALT}, \mathrm{U} / \mathrm{L}$ & $22.84(18.27,36.72)$ & $22.34(17.79,36.40)$ & $Z=-0.434$ & 0.665 \\
\hline AST, U/L & $21.55(18.84,28.10)$ & $21.55(17.33,27.56)$ & $Z=-0.591$ & 0.555 \\
\hline GGT, U/L & $33.15(22.38,47.95)$ & $29.14(18.47,47.54)$ & $Z=-1.075$ & 0.285 \\
\hline$A L P, U / L$ & $71.83 \pm 15.31$ & $68.47 \pm 19.99$ & $t=1.049$ & 0.296 \\
\hline $\mathrm{TG}, \mathrm{mmol} / \mathrm{L}$ & $1.73(1.16,2.26)$ & $1.44(1.17,2.17)$ & $Z=-0.624$ & 0.532 \\
\hline $\mathrm{TC}, \mathrm{mmol} / \mathrm{L}$ & $5.42 \pm 0.80$ & $5.53 \pm 0.87$ & $t=-0.688$ & 0.493 \\
\hline $\mathrm{HDL}, \mathrm{mmol} / \mathrm{L}$ & $1.18(1.05,1.29)$ & $1.21(1.02,1.35)$ & $Z=-0.331$ & 0.740 \\
\hline $\mathrm{LDL}, \mathrm{mmol} / \mathrm{L}$ & $3.30(2.95,3.50)$ & $3.40(3.17,3.67)$ & $Z=-1.833$ & 0.067 \\
\hline TBIL, umol/L & $11.90(9.80,14.62)$ & $13.90(10.10,17.90)$ & $Z=-1.258$ & 0.208 \\
\hline $\mathrm{FPG}, \mathrm{mmol} / \mathrm{L}$ & $4.94(4.50,5.80)$ & $4.96(4.61,5.96)$ & $Z=-0.060$ & 0.952 \\
\hline
\end{tabular}

that NAFLD-related mortality not only referred to the liver itself, but also companied with the complication such as the increased risk of CHD [33, 34]. NAFLD could aggravate insulin resistance in the body and liver that cause atherosclerotic dyslipidemia, and release a variety of pro-inflammatory, pro-coagulant, and pro-fibrotic mediators, which may play an important role in the pathophysiology of cardiac and arrhythmia complications [33, 35]. Single nucleotide polymorphism (SNP) as a significant genetic factor, plays an important role in the development of NAFLD and CHD [36, 37]. Multiple studies have confirmed that TRIB1 gene polymorphisms can increase the risk of NAFLD and the risk of $\mathrm{CHD}[28,29,38]$. In this study, we investigated the relationship of TRIB1 rs17321515 gene polymorphism with the risk of CHD, and the risk of CHD in NAFLD patients in Chinese Han population for the first time. The results showed that TRIB1 rs17321515 GA + AA genotypes were significantly associated with the increased risk of CHD in healthy controls and NAFLD patients.

Tribbles-1 (TRIB1) is one of the member of tribbles family which were first identified in Drosophila and possess the function to regulate the cell division and migration [39]. Previous studies confirmed that TRIB1 encodes a human homologue of the Drosophila tribbles protein, and the relationship of TRIB1 variant with the serum lipids metabolism was discovered by GWAS in the European population [40, 41]. To further explore the role of TRIB1 in lipoprotein metabolism, Burkhardt et al. found the serum levels of TG and

Table 8 Clinical Characteristics of TRIB1 rs17321515 A allele Carriers and Non-carriers in the CHD Patients

\begin{tabular}{|c|c|c|c|c|}
\hline Parameters & Carriers $(n=102)$ & Non-carriers $(n=39)$ & Statistics & $P$ value \\
\hline Male/Female & $50 / 52$ & 20/19 & $x^{2}=0.058$ & 0.810 \\
\hline Age, y & $66.12 \pm 9.96$ & $68.10 \pm 12.61$ & $t=-0.883$ & 0.381 \\
\hline $\mathrm{BMI}, \mathrm{kg} / \mathrm{m}^{2}$ & $24.22(22.76,25.71)$ & $24.51(22.50,26.26)$ & $Z=-0.199$ & 0.843 \\
\hline $\mathrm{ALT}, \mathrm{U} / \mathrm{L}$ & $18.88(14.74,33.03)$ & $20.27(12.81,43.41)$ & $Z=-0.018$ & 0.985 \\
\hline AST, U/L & $22.13(16.22,36.05)$ & $22.73(16.89,43.23)$ & $Z=-0.249$ & 0.803 \\
\hline GGT, U/L & $23.64(17.30,36.65)$ & $25.98(16.89,46.81)$ & $Z=-0.350$ & 0.726 \\
\hline$A L P, U / L$ & $84.87(67.18,110.11)$ & $74.64(62.40,108.33)$ & $Z=-0.843$ & 0.399 \\
\hline $\mathrm{TG}, \mathrm{mmol} / \mathrm{L}$ & $1.21(0.90,1.69)$ & $1.27(0.92,1.59)$ & $Z=-0.549$ & 0.583 \\
\hline $\mathrm{TC}, \mathrm{mmol} / \mathrm{L}$ & $4.15(3.59,5.11)$ & $4.07(3.68,5.13)$ & $Z=-0.108$ & 0.914 \\
\hline $\mathrm{HDL}, \mathrm{mmol} / \mathrm{L}$ & $0.98(0.85,1.16)$ & $1.01(0.82,1.25)$ & $Z=-0.904$ & 0.366 \\
\hline $\mathrm{LDL}, \mathrm{mmol} / \mathrm{L}$ & $2.49(2.02,3.23)$ & $2.30(2.08,3.17)$ & $Z=-0.452$ & 0.651 \\
\hline TBIL, umol/L & $13.30(10.67,17.92)$ & $15.40(10.60,18.69)$ & $Z=-0.924$ & 0.355 \\
\hline $\mathrm{FPG}, \mathrm{mmol} / \mathrm{L}$ & $5.31(4.82,6.43)$ & $4.89(4.37,5.55)$ & $Z=-2.307$ & 0.021 \\
\hline
\end{tabular}


Table 9 Clinical Characteristics of TRIB1 rs17321515 A allele Carriers and Non-carriers in the NAFLD+CHD Patients

\begin{tabular}{|c|c|c|c|c|}
\hline Parameters & Carriers $(n=94)$ & Non-carriers $(n=60)$ & Statistics & $P$ value \\
\hline Male/Female & $50 / 44$ & $30 / 30$ & $x^{2}=0.149$ & 0.699 \\
\hline Age, y & $63.34 \pm 10.53$ & $66.58 \pm 10.92$ & $t=-1.837$ & 0.068 \\
\hline $\mathrm{BMI}, \mathrm{kg} / \mathrm{m}^{2}$ & $25.54 \pm 3.24$ & $25.35 \pm 3.21$ & $t=0.344$ & 0.731 \\
\hline$A L T, U / L$ & $23.72(17.16,37.60)$ & $23.30(14.58,32.86)$ & $Z=-1.106$ & 0.269 \\
\hline AST, U/L & $21.72(17.37,32.15)$ & $20.12(15.67,32.54)$ & $Z=-0.728$ & 0.467 \\
\hline GGT, U/L & $32.39(22.76,44.39)$ & $29.28(19.67,40.77)$ & $Z=-1.384$ & 0.166 \\
\hline$A L P, U / L$ & $80.61(65.89,98.21)$ & $76.27(62.27,89.86)$ & $Z=-0.947$ & 0.344 \\
\hline $\mathrm{TG}, \mathrm{mmol} / \mathrm{L}$ & $1.70(1.31,2.21)$ & $1.40(1.00,2.09)$ & $Z=-1.932$ & 0.053 \\
\hline $\mathrm{TC}, \mathrm{mmol} / \mathrm{L}$ & $4.66(3.73,5.67)$ & $4.54(3.75,5.34)$ & $Z=-0.943$ & 0.346 \\
\hline $\mathrm{HDL}, \mathrm{mmol} / \mathrm{L}$ & $1.04(0.92,1.17)$ & $0.95(0.82,1.08)$ & $Z=-2.435$ & 0.015 \\
\hline $\mathrm{LDL}, \mathrm{mmol} / \mathrm{L}$ & $2.80(2.08,3.46)$ & $2.88(2.03,3.33)$ & $Z=-0.369$ & 0.712 \\
\hline TBIL, umol/L & $13.30(9.70,17.07)$ & $12.48(9.42,16.48)$ & $Z=-0.513$ & 0.608 \\
\hline $\mathrm{FPG}, \mathrm{mmol} / \mathrm{L}$ & $5.64(4.65,7.16)$ & $5.79(4.67,6.87)$ & $Z=-0.371$ & 0.711 \\
\hline
\end{tabular}

cholesterol were inversely associated with the expression of hepatic TRIB1 in mice [17]. Several studies had reported the effect of TRIB1 rs17321515 on the serum lipids metabolism. In a Chinese Han cohort study, TRIB1 rs17321515 AA genotype carriers had higher TG level than GG genotype carriers [42]. Katalin et al. also found that TRIB1 rs17321515 AA genotype carriers had higher serum TG and TC levels than GG + GA genotypes carriers [43]. In consideration of the higher mortality rate of NAFLD-related CHD than the single liver disease, it is meaningful to investigate the effect of TRIB1 rs17321515 gene polymorphism on the risk of CHD in general population and NAFLD patients, and the effect on the serum lipids levels $[4,44]$. In this study, we observed that TRIB1 rs17321515 $\mathrm{AA}+\mathrm{GA}$ genotypes were significantly associated with the risk of $\mathrm{CHD}$ in general Chinese Han population, Besides,
TRIB1 rs17321515 AA+GA genotypes carriers in NAFLD patients had a higher CHD risk than GG genotype carriers. Our results showed that TRIB1 rs17321515 polymorphism was a significant risk factor for $\mathrm{CHD}$ in the general population and could increase the CHD risk in NAFLD patients in Chinese Han population. Moreover, TRIB1 rs17321515 A allele could affect the serum lipids levels such as FPG, HDL, and TC in each group. Our conclusion is consistent with the previous studies which were conducted in other countries $[26,43,45]$.

Some limitations of our study must be acknowledged. Firstly, all the included subjects in this study are Chinese Han nationality, our conclusion may not be applicable to other nationality absolutely. Secondly, lacking of liver biopsy is the main limitation of our study, however, liver biopsy is invasive, and may lead to a small probability of

Table 10 Clinical Characteristics of TRIB1 rs17321515 A allele Carriers and Non-carriers in the Healthy Controls

\begin{tabular}{|c|c|c|c|c|}
\hline Parameters & Carriers $(n=98)$ & Non-carriers $(n=67)$ & Statistics & $P$ value \\
\hline Male/Female & $52 / 46$ & $34 / 33$ & $x^{2}=0.085$ & 0.770 \\
\hline Age, y & $62.00(53.00,69.00)$ & $63.00(52.00,68.00)$ & $Z=-0.349$ & 0.727 \\
\hline $\mathrm{BMI}, \mathrm{kg} / \mathrm{m}^{2}$ & $22.27 \pm 2.81$ & $22.66 \pm 3.02$ & $t=-0.850$ & 0.397 \\
\hline $\mathrm{ALT}, \mathrm{U} / \mathrm{L}$ & $17.93(12.50,25.86)$ & $19.70(12.57,23.82)$ & $Z=-0.041$ & 0.967 \\
\hline AST, U/L & $19.94(12.28,25.69)$ & $20.87(18.10,23.01)$ & $Z=-0.075$ & 0.940 \\
\hline GGT, U/L & $20.05(15.15,30.21)$ & $19.59(15.59,31.89)$ & $Z=-0.071$ & 0.943 \\
\hline$A L P, U / L$ & $69.92(57.31,82.96)$ & $66.73(54.60,83.63)$ & $Z=-0.493$ & 0.622 \\
\hline $\mathrm{TG}, \mathrm{mmol} / \mathrm{L}$ & $1.13(0.86,1.65)$ & $1.08(0.88,1.67)$ & $Z=-0.017$ & 0.987 \\
\hline $\mathrm{TC}, \mathrm{mmol} / \mathrm{L}$ & $4.85(4.30,5.32)$ & $4.24(3.44,5.00)$ & $Z=-3.263$ & 0.001 \\
\hline $\mathrm{HDL}, \mathrm{mmol} / \mathrm{L}$ & $1.35(1.06,1.51)$ & $1.28(1.03,1.40)$ & $Z=-1.175$ & 0.240 \\
\hline $\mathrm{LDL}, \mathrm{mmol} / \mathrm{L}$ & $3.11 \pm 0.77$ & $3.09 \pm 0.59$ & $t=0.173$ & 0.863 \\
\hline TBIL, umol/L & $11.55(9.37,15.22)$ & $12.30(9.50,15.10)$ & $Z=-0.484$ & 0.628 \\
\hline $\mathrm{FPG}, \mathrm{mmol} / \mathrm{L}$ & $4.56(4.11,5.05)$ & $4.50(4.04,4.97)$ & $Z=-0.616$ & 0.538 \\
\hline
\end{tabular}


serious morbidity. Thereby, we used abdominal ultrasound to diagnose NAFLD in the present study. Thirdly, some of our subjects were long-term users of lipid-lowering drugs, which will affect the accuracy of the results to some extent. Lastly, nutraceuticals can influence the lipids levels [46], but we did not consider this factor in this study.

\section{Conclusion}

In summary, we investigated the relationship of TRIB1 rs17321515 with the risk of CHD in general population and NAFLD patients in Chinese Han population for the first time. Our results showed that TRIB1 rs17321515 AA+GA genotypes are associated with an increased risk of CHD in general population and NAFLD patients, and the rs17321515 A allele affects the serum lipids levels of multiple lipid profiles in included subjects. Diverse ethnic groups and larger sample sizes are needed to investigate in further study to confirm the present data.

\begin{abstract}
Abbreviations
AASLD: American association for the study of liver diseases; ALP: Alkaline phosphatase; ALT: Alanine aminotransferase; AST: Aspartate aminotransferase; BMI: Body mass index; CHD: Coronary heart disease; ChREBP: Carbohydrateresponsive element-binding protein;" Cl: Confidence intervals; EDTA: Ethylene diamine tetraacetic acid; FPG: Fasting plasma glucose; GGT: Gammaglutamyltranspeptidase; GWAS: Genome-wide association study; HDL: High density lipoprotein; LDL: Low density lipoprotein; MTTP: Microsomal triglyceride transfer protein; NAFL: Non-alcoholic fatty liver; NAFLD: Nonalcoholic fatty liver disease; NASH: Non-alcoholic steatohepatitis; ORs: Odds ratios; PCR: Polymerase chain reaction; SNP: Single nucleotide polymorphism TBIL: Total bilirubin; TC: Total cholesterol; TG: Triglycerides; TRIB1: Tribbles 1
\end{abstract}

\section{Authors' contributions}

Study concept and design: LQ and XYN. Subjects collection: LQ, LSS, ZZZ, ZBT, DSX, and JWW. Acquisition and analysis of data: LQ and LSS. The drafting and writing of the manuscript: LQ and LSS. The revision of the manuscript: XYN. All authors approved the final manuscript.

\section{Funding}

This study was supported by Grants of National Natural Science Foundation of China (31770837) and the Qingdao People's Livelihood Science and technology plan (18-6-1-68-nsh).

\section{Availability of data and materials}

None.

\section{Ethics approval and consent to participate}

The study protocol was approved by the Ethics Committee of Qingdao Municipal Hospital before participation (Approval NO.2017-20). All the subjects have signed written informed consent.

\section{Consent for publication}

Not applicable.

\section{Competing interests}

The authors declare that they have no competing interests.

\section{Author details}

${ }^{1} T$ The Affiliated Qingdao Municipal Hospital of Qingdao University, Qingdao 266011, China. ${ }^{2}$ Department of Infectious Disease, The Affiliated Qingdao Municipal Hospital of Qingdao University, 1 Jiaozhou Road, Qingdao 266011, Shandong Province, China. ${ }^{3}$ Central Laboratories, The Affiliated Qingdao Municipal Hospital of Qingdao University, Qingdao 266071, China. ${ }^{4}$ Department of Gastroenterology, The Affiliated Qingdao Municipal Hospital of Qingdao University, Qingdao 266011, China. ${ }^{5}$ Digestive Disease Key Laboratory of Qingdao, Qingdao 266071, China.
Received: 3 July 2019 Accepted: 15 August 2019

Published online: 31 August 2019

\section{References}

1. Cha JY, Kim DH, Chun KH. The role of hepatic macrophages in nonalcoholic fatty liver disease and nonalcoholic steatohepatitis. Lab Anim Res. 2018;34: 133-9.

2. Kovalic AJ, Banerjee P, Tran QT, Singal AK, Satapathy SK. Genetic and epigenetic culprits in the pathogenesis of nonalcoholic fatty liver disease. J Clin Exp Hepatol. 2018;8:390-402.

3. Wong WW. Current prevention and treatment options for NAFLD. Adv Exp Med Biol. 2018;1061:149-57.

4. Li XL, Sui JQ, Lu LL, Zhang NN, Xu X, Dong QY, Xin YN, et al. Gene polymorphisms associated with non-alcoholic fatty liver disease and coronary artery disease: a concise review. Lipids Health Dis. 2016;15:53.

5. Tarantino G, Caputi A. JNKs, insulin resistance and inflammation: a possible link between NAFLD and coronary artery disease. World I Gastroenterol. 2011;17:3785-94.

6. Mantovani A, Ballestri S, Lonardo A, Targher G. Cardiovascular disease and myocardial abnormalities in nonalcoholic fatty liver disease. Dig Dis Sci. 2016;61:1246-67.

7. Wojcik-Cichy K, Koslinska-Berkan E, Piekarska A. The influence of NAFLD on the risk of atherosclerosis and cardiovascular diseases. Clin Exp Hepatol. 2018;4:1-6.

8. Severson TJ, Besur S, Bonkovsky HL. Genetic factors that affect nonalcoholic fatty liver disease: a systematic clinical review. World J Gastroenterol. 2016; 22:6742-56

9. Vassalle C, Andreassi MG. Genetic polymorphisms of the natriuretic peptide system in the pathogenesis of cardiovascular disease: what lies on the horizon? Clin Chem. 2009;55:878-87.

10. Mirmiran P, Esfandiar Z, Hosseini-Esfahani F, Koochakpoor G, Daneshpour MS, Sedaghati-Khayat B, Azizi F. Genetic variations of cholesteryl ester transfer protein and diet interactions in relation to lipid profiles and coronary heart disease: a systematic review. Nutr Metab (Lond). 2017;14:77.

11. Eslam M, Valenti L, Romeo S. Genetics and epigenetics of NAFLD and NASH: clinical impact. J Hepatol. 2018;68:268-79.

12. Sookoian S, Pirola CJ. Genetic predisposition in nonalcoholic fatty liver disease. Clin Mol Hepatol. 2017;23:1-12.

13. Kozlitina J, Smagris E, Stender S, Nordestgaard BG, Zhou HH, TybjaergHansen A, Vogt TF, et al. Exome-wide association study identifies a TM6SF2 variant that confers susceptibility to nonalcoholic fatty liver disease. Nat Genet. 2014;46:352-6.

14. Momeni-Moghaddam MA, Asadikaram G, Akbari H, Abolhassani M, Masoumi M, Nadimy Z, Khaksari M. CD36 gene polymorphism rs1761667 (G > a) is associated with hypertension and coronary artery disease in an Iranian population. BMC Cardiovasc Disord. 2019;19:140

15. Mangalarapu M, Vinukonda S, Komaravalli PL, Nagula P, Koduganti RR, Korripally P, Sagurthi SR. Association of CDKN2BAS gene polymorphism with periodontitis and coronary artery disease from south Indian population. Gene. 2019;710:324-32.

16. Kim IJ, Kim SH, Cha DH, Lim SW, Moon JY, Kim JO, Ryu CS, et al. Association of COX2 -765G>C promoter polymorphism and coronary artery disease in Korean population. Genes Genomics. 2019;41:1055-62.

17. Burkhardt R, Toh SA, Lagor WR, Birkeland A, Levin M, Li X, Robblee $M$, et al. Trib1 is a lipid-and myocardial infarction-associated gene that regulates hepatic lipogenesis and VLDL production in mice. J Clin Invest. 2010;120: $4410-4$.

18. Makishima S, Boonvisut S, Ishizuka Y, Watanabe K, Nakayama K, Iwamoto S. Sin3A-associated protein, $18 \mathrm{kDa}$, a novel binding partner of TRIB1, regulates MTTP expression. J Lipid Res. 2015;56:1145-52.

19. Bauer RC, Yenilmez BO, Rader DJ. Tribbles-1: a novel regulator of hepatic lipid metabolism in humans. Biochem Soc Trans. 2015;43:1079-84.

20. Soubeyrand S, Martinuk A, Lau P, McPherson R. TRIB1 is regulated posttranscriptionally by proteasomal and non-proteasomal pathways. PLoS One. 2016;11:e0152346.

21. Iwamoto S, Boonvisut S, Makishima S, Ishizuka Y, Watanabe K, Nakayama K. The role of TRIB1 in lipid metabolism; from genetics to pathways. Biochem Soc Trans. 2015;43:1063-8.

22. Ikeoka T, Hayashida N, Nakazato M, Sekita T, Murata-Mori F, Ando T, Abiru N, et al. The a>T polymorphism of the tribbles homolog 1 gene is associated 
with serum triglyceride concentrations in Japanese community-dwelling women. Tohoku J Exp Med. 2014;233:149-53.

23. Shen Y, Xi B, Zhao X, Cheng H, Hou D, Wu L, Wang X, et al. Common genetic variants associated with lipid profiles in a Chinese pediatric population. Hum Genet. 2013;132:1275-85.

24. Walia GK, Gupta V, Aggarwal A, Asghar M, Dudbridge F, Timpson N, Singh NS, et al. Association of common genetic variants with lipid traits in the Indian population. PLoS One. 2014;9:e101688.

25. Varga TV, Sonestedt E, Shungin D, Koivula RW, Hallmans G, Escher SA, Barroso I, et al. Genetic determinants of long-term changes in blood lipid concentrations: 10-year follow-up of the GLACIER study. PLoS Genet. 2014; 10:e1004388.

26. Douvris A, Soubeyrand S, Naing T, Martinuk A, Nikpay M, Williams A, Buick J, et al. Functional analysis of the TRIB1 associated locus linked to plasma triglycerides and coronary artery disease. J Am Heart Assoc. 2014;3:e000884.

27. Ghouri N, Preiss D, Sattar N. Liver enzymes, nonalcoholic fatty liver disease, and incident cardiovascular disease: a narrative review and clinical perspective of prospective data. Hepatology. 2010;52:1156-61.

28. Kitamoto A, Kitamoto T, Nakamura T, Ogawa Y, Yoneda M, Hyogo H, Ochi H, et al. Association of polymorphisms in GCKR and TRIB1 with nonalcoholic fatty liver disease and metabolic syndrome traits. Endocr J. 2014:61:683-9.

29. Speliotes EK, Yerges-Armstrong LM, Wu J, Hernaez R, Kim LJ, Palmer CD, Gudnason V, et al. Genome-wide association analysis identifies variants associated with nonalcoholic fatty liver disease that have distinct effects on metabolic traits. PLoS Genet. 2011;7:e1001324.

30. Liu Q, Xue F, Meng J, Liu SS, Chen LZ, Gao H, Geng N, et al. TRIB1 rs17321515 and rs2954029 gene polymorphisms increase the risk of nonalcoholic fatty liver disease in Chinese Han population. Lipids Health Dis. 2019;18:61.

31. Rickham PP. Human experimentation. Code of Ethics of the World Medical Association Declaration of Helsinki. Br Med J. 1964;2:177.

32. Fan JG, Jia JD, Li YM, Wang BY, Lu LG, Shi JP, Chan LY, et al. Guidelines for the diagnosis and management of nonalcoholic fatty liver disease: update 2010: (published in Chinese on Chinese journal of hepatology 2010; 18:163166). J Dig Dis. 2011;12:38-44.

33. Ballestri S, Lonardo A, Bonapace S, Byrne CD, Loria P, Targher G. Risk of cardiovascular, cardiac and arrhythmic complications in patients with non-alcoholic fatty liver disease. World J Gastroenterol. 2014;20: 1724-45.

34. Sinn DH, Kang D, Chang Y, Ryu S, Gu S, Kim H, Seong D, et al. Non-alcoholic fatty liver disease and progression of coronary artery calcium score: a retrospective cohort study. Gut. 2017:66:323-9.

35. Mangi MA, Rehman H, Minhas AM, Rafique M, Bansal V, Constantin J. Nonalcoholic fatty liver disease association with cardiac arrhythmias. Cureus. 2017;9:e1165.

36. Feitosa MF, Reiner AP, Wojczynski MK, Graff M, North KE, Carr JJ, Borecki IB. Sex-influenced association of nonalcoholic fatty liver disease with coronary heart disease. Atherosclerosis. 2013;227:420-4.

37. Choi SY, Kim D, Kim HJ, Kang JH, Chung SJ, Park MJ, Kim YS, et al. The relation between non-alcoholic fatty liver disease and the risk of coronary heart disease in Koreans. Am J Gastroenterol. 2009;104:1953-60.

38. Varbo A, Benn M, Tybjaerg-Hansen A, Grande P, Nordestgaard BG. TRIB1 and GCKR polymorphisms, lipid levels, and risk of ischemic heart disease in the general population. Arterioscler Thromb Vasc Biol. 2011;31:451-7.

39. Lohan F, Keeshan $\mathrm{K}$. The functionally diverse roles of tribbles. Biochem Soc Trans. 2013;41:1096-100.

40. Kathiresan S, Melander O, Guiducci C, Surti A, Burtt NP, Rieder MJ, Cooper GM, et al. Six new loci associated with blood low-density lipoprotein cholesterol, high-density lipoprotein cholesterol or triglycerides in humans. Nat Genet. 2008:40:189-97.

41. Hegedus Z, Czibula A, Kiss-Toth E. Tribbles: a family of kinase-like proteins with potent signalling regulatory function. Cell Signal. 2007;19:238-50.

42. Wang L, Jing J, Fu Q, Tang X, Su L, Wu S, Li G, et al. Association study of genetic variants at newly identified lipid gene TRIB1 with coronary heart disease in Chinese Han population. Lipids Health Dis. 2015;14:46.

43. Sumegi K, Jaromi L, Magyari L, Kovesdi E, Duga B, Szalai R, Maasz A, et al. Functional variants of lipid level modifier MLXIPL, GCKR, GALNT2, CILP2, ANGPTL3 and TRIB1 genes in healthy Roma and Hungarian populations. Pathol Oncol Res. 2015;21:743-9.

44. Liu H, Lu HY. Nonalcoholic fatty liver disease and cardiovascular disease. World J Gastroenterol. 2014;20:8407-15.
45. Ollila HM, Utge S, Kronholm E, Aho V, Van Leeuwen W, Silander K, Partonen T, et al. TRIB1 constitutes a molecular link between regulation of sleep and lipid metabolism in humans. Transl Psychiatry. 2012;2:e97.

46. Scicchitano P, Cameli M, Maiello M, Modesti PA, Muiesan ML, Novo S, Palmiero $P$, et al. Nutraceuticals and dyslipidaemia: beyond the common therapeutics. J Funct Foods. 2014;6:11-32.

\section{Publisher's Note}

Springer Nature remains neutral with regard to jurisdictional claims in published maps and institutional affiliations.
Ready to submit your research? Choose BMC and benefit from:

- fast, convenient online submission

- thorough peer review by experienced researchers in your field

- rapid publication on acceptance

- support for research data, including large and complex data types

- gold Open Access which fosters wider collaboration and increased citations

- maximum visibility for your research: over $100 \mathrm{M}$ website views per year

At BMC, research is always in progress.

Learn more biomedcentral.com/submissions 